PENGARUH ETIKA TERHADAP NIAT MELAKUKAN

WHISTLEBLOWING DENGAN RETALIASI SEBAGAI VARIABEL MODERATING

TESIS

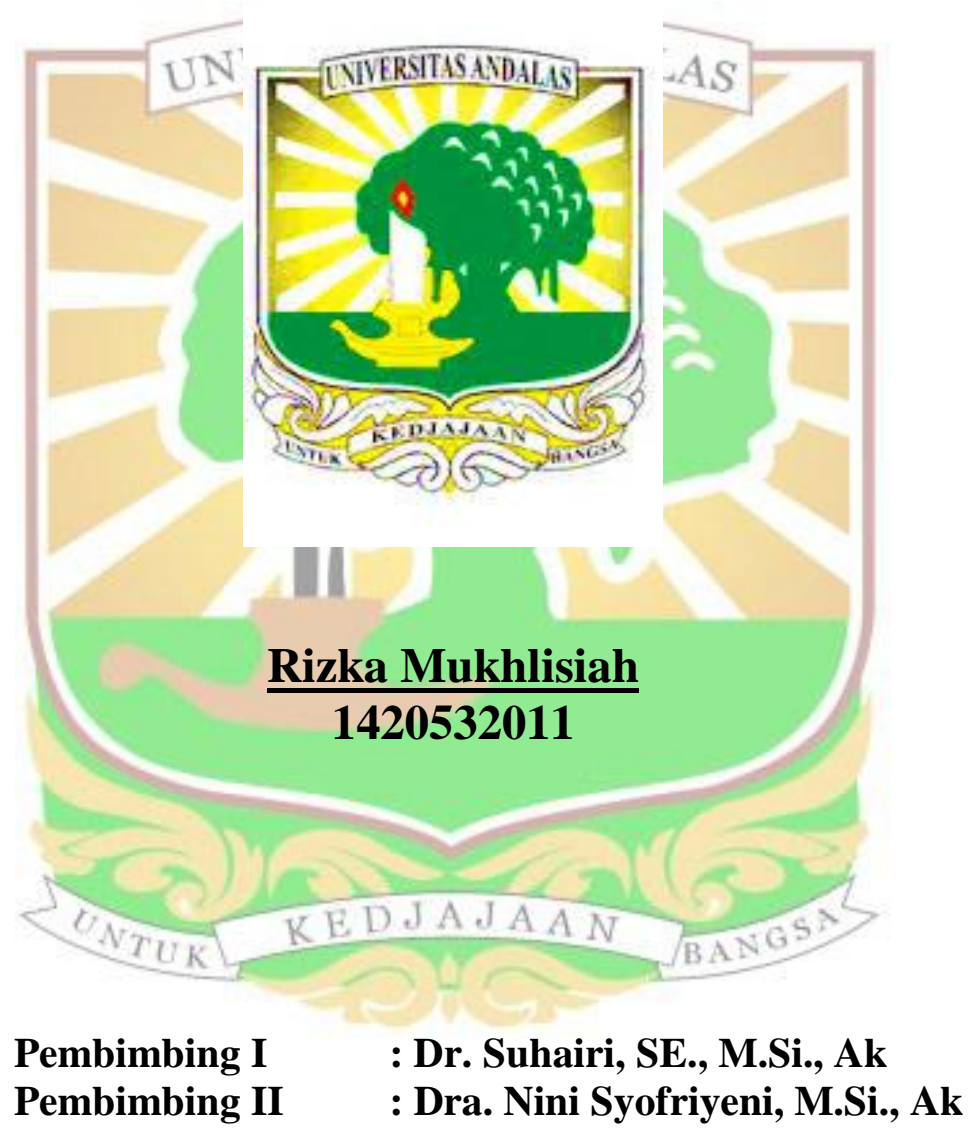

PROGRAM STUDI MAGISTER AKUNTANSI

PROGRAM MAGISTER DAN DOKTOR FAKULTAS EKONOMI UNIVERSITAS ANDALAS

PADANG

2017 


\title{
PENGARUH ETIKA TERHADAP NIAT MELAKUKAN WHISTLEBLOWING DENGAN RETALIASI SEBAGAI VARIABEL MODERATING
}

\author{
RIZKA MUKHLISIAH \\ Pascasarjana Universitas Andalas \\ Email: riska8856@gmail.com
}

\begin{abstract}
ABSTRAK
Penelitian ini bertujuan untuk menguji pengaruh etika terhadap niat

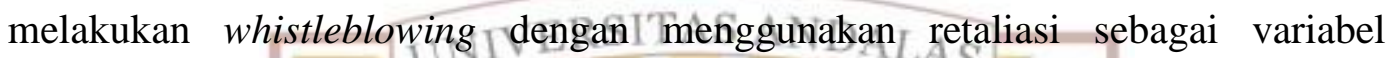
moderating pada karyawan yang bekerja di kantor BPKP Provinsi Sumatera Barat dan Inspektprat Provinsi Sumatera Barat.

Data yang digunakan adalah data primer dengan menggunkan kuesioner. Penentuan sampel dengan menggunakan metode pengumpulan data yang disebut purposive sampling, yaitu karyawan yang bekerja pada BPKP Provinsi Sumatera Barat dan karyawan yang bekerja pada Inspektorat Provinsi Sumatera Barat. Jumlah sampel yang dapat digunakan yaitu sebanyak 80 responden. Data yang diperoleh dianalisis dengan menggunakan teknik analisis PLS (Partial Least Square) melalui software SmartPLS.

Hasil penelitian menunjukkan bahwa etika tidak dapat mempengaruhi niat melakukan whistleblowing pada karyawan BPKP Provinsi Sumatera Barat dan karyawan Inspektorat Provinsi Sumatera Barat. Selanjutnya retaliasi berpengaruh positif terhadap niat melakukan whistleblowing pada karyawan BPKP Provinsi Sumatera Barat dan karyawan Inspektorat Provinsi Sumatera Barat.. Hasil penelitian ini juga menunjukkan bahwa retaliasi tidak dapat memoderasi etika terhadap niat melakukan whistleblowing pada karyawan BPKP Provinsi Sumatera Barat dan karyawan Inspektorat Provinsi Sumatera Barat.
\end{abstract}

Kata Kunci: Etika, Retaliasi, Niat Melakukan Whistleblowing 


\title{
PENGARUH ETIKA TERHADAP NIAT MELAKUKAN WHISTLEBLOWING DENGAN RETALIASI SEBAGAI VARIABEL MODERATING
}

\author{
RIZKA MUKHLISIAH \\ Pascasarjana Universitas Andalas \\ Email: riska8856@gmail.com
}

\begin{abstract}
This study to examine the effect on the ethical conduct by using the whistleblowing intention retaliation as moderating variable on the employees who work in the office BPKP West Sumatra Province and Inspectorate West Sumatra Province.

The data used are primary data by using a questionnaire. The samples using the method of data collection is called purposive sampling, ie employees who work at BPKP West Sumatra Province and employees working in the Inspectorate of West Sumatra Province. The number of samples that can be used as many as 80 respondents. Data were analyzed using analysis techniques PLS (Partial Least Square) through software SmartPLS.

The results showed that ethics can not affect the intention do whistleblowing employees BPKP West Sumatra Provincial and Inspectorate West Sumatra Provincial. Furthermore retaliation positive influence on the intention do whistleblowing employees BPKP West Sumatra Provincial and Inspectorate West Sumatra Provincial. The results also show that retaliation can not moderate the intentions of doing ethics whistleblowing employees BPKP West Sumatra and Inspectorate West Sumatra Provincial.
\end{abstract}

Keywords: Ethics, retaliation, Whistleblowing Intention

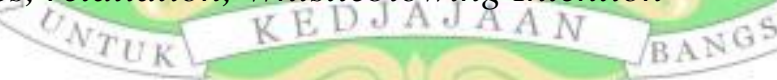

